\section{THE WEED PROBLEM*}

\author{
By PROF. E. J. SALISBURY, C.B.E., F.R.S.
}

$\mathrm{T}$ $O$ define a weed is not an easy matter since this term of opprobrium is applied in different ways by different persons. Probably the best definition is that of a plant growing where we do not want it. Nevertheless to many the designation implies a certain measure of uncontrollability, and it is more particularly these weeds, which are the bane of the farmer and the gardener, that concern us here.

It has been estimated that, before the War, the cost of weeds to Great Britain was of the order of some sixteen and a half million pounds a year. It is, indeed, probable that this is a very conservative estimate, since the monetary losses due to the indirect effects of weeds, which are by no means inconsiderable, are well-nigh impossible to assess.

The most evident effect of weeds is that they compete, with our crop and garden plants, for such essenials as water, the mineral nutrients necessary for all types of vegetation in smaller or larger degree, the carbon dioxide of the air, and for the radiant energy upon which the manufacture of sugars by the green leaf depends.

The competition for the soil moisture is of a dual character. If plants are growing in a very wet soil the amount of water which the plant can take up, provided there is adequate aeration, is probably determined more by the efficiency of the internal water-conducting system than by the extent of its roots. But when the moisture in the soil is low in amount the extent of the absorbing surface of the root which is in contact with the soil is often the governing factor in the supply, and it is naturally under just these conditions that the water supply is most important. The extent of the root system is also of importance as affecting the amount of nutrients available to the plant, since upon this will depend the volume of soil exploited. This is especially true with respect to those nutrients in regard to which the soil is most deficient.

The development of the root system of a plant is now known to be greatly influenced not only by the aeration and texture of the soil but also by the presence of root systems. The mechanism of this interference is not yet fully understood. It is likely that the intake of oxygen and the release of carbon dioxide during the respiration of roots may play an appreciable part. Indeed, most roots are intolerant of high concentrations of carbon dioxide in the soil atmosphere. The presence of numerous weed roots will therefore compete for the available oxygen and render the soil atmosphere less favourable for root development and the intake of nutrients. In addition there is experimental evidence that soluble substances are produced by roots, perhaps during the breakdown of dead cells, which are of a toxic nature and vary in their deleterious character according to the species concerned.

Some astonishing figures have been obtained by the Canadian botanist Pavlychenko showing the extent of the root system of cereals when grown with and without the competition of other plants. When wheat and rye were raised as single individuals with no other vegetation in their neighbourhood and measured as if all the roots were cut off and placed end to end, as one continuous thread, the total length

- Substance of a lecture delivered at the Royal Institution on April 30. was more than forty-four miles for a wheat plant and more than fifty miles for one of rye. When grown in drills, as in normal cultivation, so that the erop plants in the same row compete with one another, the root-lengths diminished to from one half to two thirds of a mile, while when weeds were present in addition, between the rows of cereals, the total length was only about one ninth of a mile. The presence of charlock in a field of wheat can reduce the root system of the cereal to one fifth or even a tenth of its extent when weeds are absent.

There is reason to believe that root competition and the resulting effects upon the supply of nutrients may often be the most important of the deleterious effects brought about by weeds. Weeds thus deprive our crop and garden plants of water and nutrients in two ways. First by reducing the volume of soil occupied, and secondly by depleting those essential requirements which the diminished volume of soil contains.

Sometimes the chief nutrient thus depleted is nitrogenous material, and the harmful influence of some weeds can be greatly alleviated by applications of nitrogenous fertilizers. Even where there is no root-competition, mere crowding, as Dr. Brenchley showed with plants in separate eontainers in water culture, in itself increases this nitrogen requirement. But it must be emphasized that the nearer any nutrient is to the minimum requisite for crop growth, the more likely it is that the presence of weeds will bring about a real deficiency.

We know that weeds absorb the essential elements in very different amounts. Thus the common bracken contains an exceptionally high proportion of potash, so that plants in competition with bracken are liable to suffer from potash starvation, but for the same reason bracken fronds, cut early in the season, provide a most useful material for composting in these days of shortage in potash supplies.

We now know that broad beans and beets, in par. ticular, require minute traces of boron, and possibly all plants require some. Lack of minute quantities of copper and cobalt in a soil, and hence in the herbage developing upon it, may lead to serious and even fatal diseases in sheep. The study of these micronutrients is as yet in its infancy, and one of the gaps in our knowledge that requires filling is in respect to the effect of weeds in influencing the availability of these essentials for healthy growth. We do know, however, that these micronutrients are often present in amounts only just adequate for the crop, and one or other is not infrequently deficient, at least in an available form.

Some weeds take up these rarer elements in quantities as great or even greater than do our garden and crop plants. It is therefore extremely likely that the presence of weeds eompeting for these micronutrients may accentuate even if they do not create deficiencies.

So far as I am aware, gold has not yet been shown to be essential for vigorous plant growth, but data obtained by the distinguished Czechoslovakian plant physiologist, Prof. B. Němec, showed that whereas a metric ton of dried maize contained only $2 \mathrm{gm}$. of gold, that objectionable weed the field horsetail (Equisetum arvense) contained $63 \mathrm{gm}$. and the marsh horsetail ( $E$. palustre) $610 \mathrm{gm}$., although the same dry weight of the soil only contained a tenth of a gram. Let me hasten to add that the yield per acre is not sufficient to warrant the cultivation of horsetails for this purpose. 
There is another aspect of the weed in relation to the rarer elements that is of considerable economic importance in certain districts. Some trace elements, far from being beneficial to stock which feeds upon the herbage containing them, are extremely poisonous. A particularly striking example is afforded by the seliniferous soils of the United States. The pastures which grow on these soils may be quite innocuous, since the comparatively insoluble selenium is only absorbed in small amounts by the grasses and many species of herbs. But certain weeds which occur in these pastures, particularly species of milk vetch (Astragalus spp.) have such a capacity for absorbing and accumulating selenium that they render the herbage highly poisonous to browsing animals. The so-called 'teart' pastures of Somerset, Gloucester and Warwickshire are now known to be deleterious to cattle owing to the presence of molybdenum in the herbage, but whereas dried rye-grass growing on these soils will contain only about one part of molybdenum in a thousand, white clover will contain about nine and a half times as much. Hence on these soils the clovers, which are desirable constituents of herbage in most areas, must be classed as weeds. Applications of ammonium sulphate to such pastures reduce their toxicity partly because there is an increased proportion of grass in the herbage but also because under the more acid conditions thus induced the uptake of the molybdenum is diminished.

These few examples suffice to show that the relation of weeds to the rarer elements is an important one concerning which far more information than at present available is desirable. The amounts involved are extremely small. It has, for example, been estimated that the requisite cobalt for healthy growth of sheep in New Zealand is of the order of one part in twenty million.

Competition for light by weeds and cultivated plants is often pronounced in the seedling stages, when weeds may form a canopy of foliage that pre; cludes all but a small fraction of the radiant energy, necessary for green leaves to manufacture the plant's food, from reaching the seedlings of our crop or garden plants. But such competition for light is by no means confined to the juvenile phases of development or to recently disturbed soil. The plantains and daisies on our lawns and golf-greens suppress the grass mainly because their close-pressed rosettes cut off the light from the turf beneath. But no better example of competition for light could perhaps be found than is exhibited by that weed of the hedgerow, the common elder (Sambucus nigra) because it illustrates in a striking manner those biological features which most commonly render species especially aggressive in this respect. The first of these is the remarkable capacity of this shrub to form robust shoots of great length in a single season. These may attain more than six feet and quickly outstrip the shoots of their neighbours. Secondly, the very early development of the new foliage, which expands before that of other deciduous hedgerow shrubs, confers a by no means unimportant advantage in time. Thus in the south of England the average date for the beginning of leaf expansion of the elder in a normal season is about the middle of February, whereas for our commonest hedgerow shrubs, the hawthorn, blackthorn and hazel, the average date is about the third or fourth week in March. Lastly the leaves of the elder are large and collectively constitute a canopy of foliage that is relatively impermeable to the light. The total effect of these features is that the elder can create an efficient sunshade above the surrounding hedge before the leaves of the other shrubs are even fully expanded. Added to which the seedlings of the elder are remarkably tolerant of deep shade, so that they can develop under conditions that might suppress other species, and are not infrequently to be found within the hedge itself.

In addition to the direct effects of weeds in depriving cultivated plants of light, water, and nutrients, there are other important indirect outcomes of their presence, particularly as host plants of pests which enable the parasites and predators to persist in an area from which the appropriate cultivated host is temporarily absent. Thus the flea beetle, which in the past season was such a devastating pest on turnips in some areas, finds an alternative host on the charlock. Weeds also harbour eelworms and virus diseases, while the slime fungus which causes club-root disease of our cabbages and other species of Brassica, is often to be found flourishing on Cruciferous weeds, particularly treacle-mustard (Sisym. brium officinale).

With respect to insect pests that attack both cropplants and weeds, our knowledge of deterrents and attractants, though at present meagre, offers the interesting possibility of treatment that shall not merely render the cultivated plants relatively immune but may also induce such insects to afford biological control of the weeds themselves.

The solution of the weed problem can only be found by concerted action directed on one hand towards weed destruction and on the other against their reappearance. Methods of destruction, especially by chemical means, are often immediately successful and even spectacular in their achievements, but they represent an expenditure of money, material and human effort that might in many instances be avoided. Preventive measures are usually far from being spectacular and indeed are apt not to be accorded the recognition they deserve.

Cultivation of the soil by hand, while affording an effective means of control of annual species and some perennials, is dependent upon an adequate supply of inexpensive manual labour. On the farm, mechanical cultivation can achieve much to mitigate the labour difficulty, but it should be remembered that the effective application of mechanical methods to the fallow and the growing crop demands forethought in the lay-out and spacing of the plants to this end. The chief drawback to cultivation as a means of weed control is that the repeated disturbance of the soil that may be required to keep the land clean is liable to do as much harm by disturbance of the roots of the cultivated plants as it does good by the destruction of the weeds.

The high cost of labour and the risk of undue root disturbance have been responsible for the development of chemical means of control by spraying. Of these the most effective so far devised is the method of spraying with a dilute solution of sulphuric acid which was utilized with very satisfactory results in the United States and France and has been successfully developed by Mr. G. E. Blackman in Great Britain for the control of weeds in onions and other crops. By the application of a suitable amount of lime the effects of the acid on the soil are neutralized. Nitric acid has also been employed and has the merit that it increases the nitrogen content of the soil which weeds are so liable to deplete. Some measure of 
control has been achieved by the use of fertilizers such as ammonium sulphate and cyanamide, and if such methods could be rendered more effective they clearly offer the advantage of avoiding expenditure of chemicals that are not in themselves of value to the crop. If more effective control by means of fertilizing sprays or dusts could be attained it would probably be greatly to the advantage of agriculture and horticulture in more ways than one. Only time can reveal the long-term influence of chemical methods on soil-structure and fertility.

Even with the most effective chemical sprays destruction of weeds is rarely complete, and those that remain, because they are freed from the competition of their neighbours, may attain a large size and in considerable measure compensate in seed yield for the small number of individuals that ripen fruit. For this reason the supplementing of mechanical or chemical control methods by hand labour may well be profitable.

On unplanted soil, drastic methods such as the application of sodium chlorate are sometimes effective against deep-rooted perennials, but little is known as to the residual effects upon the soil structure and the microscopic forms of life.

Many perennial weeds, such as the creeping thistle, the bindweed and the hoary cress, can produce shoots from quite small fragments of the roots even if these be comparatively deeply placed in the soil. Repeated destruction of the overground shoots of these until the underground parts are exhausted of their reserves of food, offer the best hope of their eradication. This has proved effective with the bracken, although the cutting has to be carried out two or three times at intervals of five or six weeks over a period of from three to five years. It has been aptly said that to stop cutting bracken before eradication is complete is like leaving a smouldering fire untended.

Biological control by the encouragement of parasites, either insect or fungal, has been utilized with varying degrees of success. Insect control has proved valuable against the cactus pest of Australia (see NATURE of September 13, 1941, p. 303). The control of bracken by means of a fungus has been attempted in Great Britain. The great difficulty in the development of biological methods is to find a parasite which is strictly limited to the kind of plant we desire to control and which will not sooner or later itself become a pest on some related or even unrelated species which we cultivate.

The weed problem is apprehended as in reality a dual one: the first being the problem of eradication, and the second the problem of preventing reinfection. The former is often far more readily accomplished than the latter, which can in general only be partially achieved.

The second category, preventive measures, are not only perhaps the most important but also their application leads us to study the biology of the weed species and thus to discover their most vulnerable points of attack.

However effectively we may have destroyed existing weeds, it is clearly imperative that they should not be re-introduced by the sowing of impurities with our seeds. Modern screening methods which take advantage of many of the differences between crop seeds and those of other plants such as size, weight, and surface texture have accomplished much, and the number of weeds that we inadvertently sow to-day are few compared with half a century ago. The former prevalence of darnel grass (Lolium temulentum), which was evidently a pest in Shakespeare's day, of the blue pimpernel (Anagallis coeru. lea), and the pheasant's eye (Adonis autumnalis), which are to-day rare cornfield weeds, was due to their repeated introduction in seed imported from the south of Europe. Even now vast quantities of weed seeds are annually sown with grass and clover seed all over Great Britain.

The returns of the official seed-testing station show that perennial rye-grass seed commonly con. tains 2-4 per cent by weight of impurities, cocksfoot seed about 9 per cent, and meadow foxtail between 30 per cent and 40 per cent. Clover seeds, too, often contain between 4 per cent and 9 per cent. To understand what such proportions of impurities mean in terms of actual weed seeds, I have calculated that in every year, with the sowing of clover and grass, more than six billion weed seeds were probably also sown throughout Great Britain.

Even could we completely clean the soil of growing weeds and ensure that no weed seeds were afterwards sown, we should probably not be free from weeds for a number of years owing to the long period over which buried weed seeds can remain alive.

Careful experiments carried out on seeds buried in the soil and then placed under conditions favourable to germination, after the lapse of increasing periods of years, have shown that the seeds of the shepherd's purse (Capsella) and fat hen (Chenopodium album) can retain their viability for at least thirty-five years, and those of the crisped dock (Rumex crispus) for at least sixty years. Others, such as those of the blue pimpernel, retain their viability for even longer periods.

Apart from viable seeds already in the soil and possible impurities in the seeds that we sow, there is another source of infection that is by no means negligible, namely, the accidental introduction in manure, on our boots and clothes, and even on the implements of agriculture. The moist heat that is generated as manure ferments, or in the compost heap, does, it is true, destroy the viability of many of the contained seeds, but many there are which can not only pass through the alimentary canal of the cow or horse with unimpaired or even enhanced germination, but also can survive the subsequent fermentation.

It is worth while dwelling somewhat on the accidental carriage and distribution of seeds by our own activities, since all too little attention has been paid to this by no means infrequent occurrence.

Some years ago I carried out a number of experi. ments designed to test the extent to which seeds were carried about in the mud upon our boots. Mud brought into churches which had paved paths leading to the porches was placed on sterilized soil and moistened. The seedlings which afterwards emerged were found to be mostly grasses, but various other weeds were also present. It is reasonable to assume that these seeds might have been carried appreciable distances before the mud dried sufficiently to fall off. Even more effective carriage in mud is accomplished in the patterned tread of motor-tyres and the wheels of farm carts and lorries, as well as those of private cars, and are an effective means of dissemination over long distances. There is little doubt that the wayside pineapple weed (Matricaria suaveolens), which originated from Oregon, owed its rapid spread 
throughout Great Britain to this means of dispersal.

Our clothes, too, are a frequent means of seed carriage, and if after a country walk one turns down the 'cuffs' of one's trousers it is amazing the collection of seeds that can be obtained. I have sowed a number of such collections after walks in diverse types of habitat. In one instance there were no less than 325 seedlings produced when the trouser brushings were sown on sterilized soil. Of this total 284 were seedlings of various grasses, while the remaining 41 comprised five different kinds of weeds.

It is important to recognize that vegetative propagation by means of shoots that arise from the roots, though an unusual feature, is characteristic of several of our most pernicious weeds such as the creeping sorrel (Rumex acetosella), the creeping thistle (Cirsium arvense, the field convolvulus (Convolvulus arvensis), and the yellow toadflax (Linaria repens). The importance of such vegetative methods is that whereas the seedling can only successfully develop in a relatively open spot where the small food reserve in the seed will enable it to grow into the light, the shoot from a root or from an underground stem has the much larger reserves of the adult parent to draw upon and so is able to extend unchecked by the shade of its neighbours.

Owing to the prolific production of seeds (for example, a single fruit of groundsel has the potentiality of infesting about sixty-five acres in three years), it cannot be urged that because the number of seeds inadvertently introduced is small, it is therefore a matter of indifference. Indeed, when we weed our gardens it is well to remind ourselves that unless the ground is cleaned completely of all weeds our efforts may merely result in the survivors attaining to large dimensions, and thus in no small degree compensating by the magnitude of their yield for the dearth of individuals.

We must, moreover, recognize that our efforts to eliminate weeds will automatically tend to render our tasks more difficult unless it is complete. So, too, in the use of large-scale weed treatment in agriculture, it is important to bear in mind that a remedy that is only partial may in fact merely destroy the strains that are more easily killed and so we leave behind the more resistant types free from the competition of their less robust relatives; hence the latter state is worse than the first, for we have selected out a strain or strains that demand more drastic measures to compass their destruction.

If our attempt at suppression is at the seedling stage, we must know whether germination is commonly 'simultaneous' or normally 'intermittent' and what is the period of dormancy of buried seeds? So, too, it is essential to our success to know the potentialities for vegetative increase. Crops of weeds like those of economic species have their soil preferences and differential response to nutritional stimulus. In South Australia it was found that the application of copper salts to copper-deficient soils resulted in an increased yield of the cereal crop amounting to from three to eight times, but the effect upon the weeds was only to increase them by 50 per cent. It is, indeed, manifest that to combat effectively the avarice of weeds it is essential to have a far more intimate acquaintance with their biology, in all its aspects, than we at present possess. 'Know thy enemy' is as sound advice in horticultural and agricultural hygiene as in any other type of activity, and perchance we may find that a species that appears in the guise of an enemy may sometimes function as a friend.

\section{X-RAY TECHNIQUE IN THE INDUSTRIAL LABORATORY*}

\author{
BY H. P. ROOKSBY
}

Research Labsratories of The General Electric Co., Ltd.

$T$

HERE are two main ways in which $\mathrm{X}$-rays have become of immense practical importance in the industrial field. The great penetrating power has been utilized in the technique of radiography for the examination of what may be described as the macrostructure of solid bodies and objects. In X-ray crystal analysis the diffraction of X-rays by the regular pattern of atoms in a crystal has been utilized to elaborate and supplement chemical and other physical methods of examining the nature and properties of a material.

\section{X-Ray Tubes}

The basic design of the modern $\mathrm{X}$-ray tube is that of an evacuated jar or envelope containing two electrodes between which a high potential is applied. In an electron tube for radiographic work, the target or positive electrode usually consists of a hollow water-cooled block of copper into the face of which is set a small disk of tungsten. The other electrode is a hot tungsten filament surrounded by a metal cap or hood, the arrangement being to focus the electron stream from the filament on to the target face in the form of a rectangle. When viewed at an incident angle of about $20^{\circ}$, the rectangular source of the primary $\mathrm{X}$-ray beam is foreshortened to a square. Comparatively compact X-ray tubes encased in oil and with shock-proof high-tension cabling are available for operation at 200 or even 400 kilovolts. Demands for radiation of great penetrating power have led to the building of units to operate at one million volts and more. One of the most recent which may be used at a million volts utilizes Freon under pressure as the insulating medium and a resonance transformer as high-tension generator. The length is only $7 \mathrm{ft}$., the X-ray tube and generator being enclosed in the one envelope ${ }^{1}$.

For erystal analysis it is not necessary to operate the $\mathrm{X}$-ray tube at voltages above $60-70$ kilovolts. Moreover, some means has to be found for simple alteration of the nature of the source of X-rays in order that several different wave-lengths are available. The requirements are best met by the continuously evacuated demountable X-ray tube, with interchangeable targets each faced with a different metal. The rectangular focus is frequently viewed at almost glancing angle so that a source of $\mathrm{X}$-rays effectively approaching a short line is obtained.

The radiation from an $\mathrm{X}$-ray tube consists, in general, of two parts, the 'white' or continuous spectrum radiation and a line radiation the wavelengths of which are characteristic of the radiating element. It is the continuous radiation which is of practical value in radiography; in the continuous spectrum there is a sharp lower limit of wave-length depending only upon the applied voltage and decreasing with increase in voltage. To a great extent the penetrating power of a heterogeneous $\mathbf{X}$-ray beam increases as the lower limit of wave-length becomes shorter, so that penetrating power may be largely controlled by the X-ray tube voltage. It must be chosen to suit the subject of examination if maximum

* Abridgement of three Cantor Lectures delivered before the Royal Society of Arts on March 16, 23 and 30. 